\title{
Repensando os cotidianos escolares: possibilidades e práticas para a desconstrução de preconceitos
}

SILVA, Daniel Henrique Oliveira ${ }^{1}$

\section{RESUMO}

A escola é um espaço dinâmico recheado de práticas plurais que ocorrem nos cotidianos escolares e que muitas vezes passam despercebidas do olhar de gestores e professores. Esse projeto de pesquisa e de ações surge justamente a partir de uma prática de preconceito ocorrida dentro da escola e denunciada por um estudante. A partir da denúncia desses preconceitos, despertei o olhar para as diferentes práticas que ocorrem dentro da escola e constituí a presente pesquisa que buscou perceber os preconceitos vividos principalmente por estudantes LGBTs (Lésbicas, gays, bissexuais, travestis e transexuais), no espaço escolar e, concomitantemente a essas pesquisas, realizei em parceria com professores da escola trabalhos buscando debater e conscientizar sobre outros diferentes preconceitos/discriminações ali presentes. A partir disso, foi possível problematizar práticas de preconceito arraigadas e presentes na escola, almejando proporcionar um ambiente de respeito às diversidades. Esses debates, posteriormente, assumiram lugar nas aulas dos professores, ao trabalharem de alguma maneira essas temáticas em suas disciplinas.

Escola. Preconceitos. LGBTs.

\section{Rethinking school routines: possibilities and practices for prejudices deconstruction}

\section{ABSTRACT}

The school is a dynamic space full of plural practices that occur in school daily life and that often go unnoticed by managers and teachers. This research and action project arises precisely from a practice of prejudice that occurred within the school and reported by a student. From the denunciation of these prejudices, we awakened our gaze to the different practices that occur within the school and constituted the present research that sought to understand the prejudices experienced mainly by LGBT students (Lesbians, gays, bisexuals, transvestites and transsexuals), in the school and, concomitantly with these surveys, there were works seeking to debate and raise awareness about other different

\footnotetext{
1 Doutorando em Educação pela Universidade do Estado do Rio de Janeiro. Lattes: http://lattes.cnpq.br/6650281205888643. ORCID: http://orcid.org/0000-0003-4345-8305.

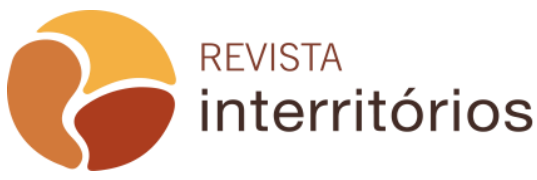


prejudices / discrimination present there. From this, it was possible to problematize ingrained prejudice practices present in the school, aiming to provide an environment of respect for diversity. These debates, later, took place in the teachers' classes, when working in some way these themes in their subjects.

School. Prejudices. LGBTs.

\section{Repensando los cotidianos escolares: posibilidades y prácticas para deconstruir prejuicios}

\section{RESUMEN}

La escuela es un espacio dinámico lleno de prácticas plurales que ocurren en la vida diaria de la escuela y que a menudo pasan desapercibidas para los gerentes y maestros. Este proyecto de investigación y acción surge precisamente de una práctica de prejuicios que ocurrieron dentro de la escuela y reportados por un estudiante. A partir de la denuncia de estos prejuicios, me desperté para observar las diferentes prácticas que ocurren dentro de la escuela y constituí la presente investigación que buscó comprender los prejuicios experimentados principalmente por estudiantes LGBT (lesbianas, gays, bisexuales, travestis y transexuales), en el espacio escolar y, simultáneamente a esta investigación, llevé a cabo, en colaboración con los maestros de escuela, acciones para debatir y crear conciencia sobre otros prejuicios/discriminaciones diferentes presentes allí. A partir de esto, fue posible problematizar las prácticas de prejuicios arraigadas y presentes en la escuela, con el objetivo de proporcionar un ambiente de respeto por la diversidad. Estos debates, más tarde, tuvieron lugar en las clases de maestros, cuando se trabajaban de alguna manera estos temas en sus asignaturas.

Escuela. Prejuicios. LGBT.

\section{Ripensare la scuola ogni giorno: possibilità e pratiche per decostruire i pregiudizi}

\section{SINTESE}

La scuola è uno spazio dinamico pieno di pratiche plurali che si verificano nella vita quotidiana della scuola e spesso passano inosservate da manager e insegnanti. Questo progetto di ricerca e azione nasce proprio da una pratica di pregiudizi verificatisi all'interno della scuola e segnalati da uno studente. Dalla denuncia di questi pregiudizi, mi sono svegliato per osservare le diverse pratiche che si verificano all'interno della scuola e hanno costituito la presente indagine che ha cercato di comprendere i pregiudizi vissuti principalmente dagli studenti LGBT (lesbiche, gay, bisessuali, travestiti e transessuali), in lo spazio scolastico e, contemporaneamente a questa ricerca, ho svolto, in collaborazione con gli



Interritórios | Revista de Educação Universidade Federal de Pernambuco, Caruaru, BRASIL | V.6 N.10 [2020] 
insegnanti della scuola, azioni di dibattito e sensibilizzazione su altri pregiudizi / discriminazioni diverse lì. Da ciò è stato possibile problematizzare le pratiche di pregiudizio radicate e presenti nella scuola, con l'obiettivo di fornire un ambiente di rispetto per la diversità. Questi dibattiti, in seguito, si sono svolti durante le lezioni degli insegnanti, quando queste materie erano in qualche modo trattate sulle loro materie.

Scuola. Pregiudizio. LGBT.

\section{INTRODUÇÃO}

Quais os preconceitos enfrentados por estudantes nas escolas de ensino fundamental e médio? Qual o papel da escola no tratamento desses atos? Quais as consequências dos preconceitos na vida de estudantes?

Esses questionamentos nortearam essa pesquisa ao entrar em contato com um relato denúncia de um estudante que sofria preconceitos na escola em que eu dava aula. Esse caso, foi relatado por um aluno de dezessete anos, do segundo ano do ensino médio, que se identifica enquanto preto e gay. Esse relato foi colhido após saber de informações de que um aluno teria sofrido homofobia por parte de uma supervisora da escola, assim, ao me preocupar com o ocorrido, busquei saber com mais detalhes e a me interessar por entender esse universo de preconceitos que perpassam os cotidianos escolares e quais as consequências deles na vida dos estudantes.

Nesse relato o estudante conta sobre os preconceitos vividos na escola:

Eu estava na escola aí a supervisora fez homofobia comigo e racismo né... foi em público... ela falou assim que por conta de eu ser gay eu iria para o inferno que eu tinha que mudar meu jeito... sofri também racismo na sala... a menina falou assim que meu cabelo era feio... que eu tinha que cortar... aí eu xinguei ela né... (risos). O caso da supervisora começou assim,,,, eu estava lá na sala aí ela falou assim, ela começou a falar, porque ela é evangélica, eu estava conversando com as meninas eu acho que é sobre meninos ela falou que eu tinha que mudar meu jeito porque isso não era certo porque eu tinha que ver porque senão eu não ia para o céu e aí no outro dia ela foi e voltou na sala e eu fui conversar com as meninas do mesmo assunto e ela falou assim que eu ia para o inferno na frente todo mundo aí os meninos ficaram me olhando de forma diferente porque já estavam meio que entendendo assunto e ela influenciou eles, meio que isso... aí o povo já começou a fazer racismo e homofobia comigo na sala e depois eu brigava com os meninos quando eles faziam isso (Estudante entrevistado, 2017). 
Esse relato possibilitou entender que os preconceitos são ainda mais profundos do que eu poderia imaginar inicialmente e partem de diferentes direções e afetam a vida dos alunos, como apontado pelo entrevistado, quando relata o preconceito que enfrentou de outros colegas de sala nas aulas de Educação Física: "às vezes eles não deixavam eu jogar futebol porque eu sou gay e eles falavam assim você não vai jogar futebol aí as vezes eu brigava com eles verbalmente mas teve uma vez que eu agredi o menino também" (Estudante entrevistado, 2017).

Essa denúncia foi feita por um aluno da escola em que eu atuava enquanto professor de história. Foi a partir dela, que no ano de 2017 eu busquei possibilidades para desenvolver algum projeto que colocasse em discussão a temática dos preconceitos. Assim, me deparei com a possibilidade colocar esse projeto em prática ao ver a abertura de um edital de pesquisa/ação do governo de Minas Gerais que possibilitava o desenvolvimento de pesquisas de Iniciação Científica no Ensino Médio por meio do projeto UBUNTU², uma parceria do Fundo de Amparo à Pesquisa de Minas Gerais - FAPEMIG com Secretaria Estadual de Educação que no período era coordenado por uma secretária de educação negra, professora da educação básica, do chão da escola, que buscava se aproximar das realidades escolares. Ao entrar em contato com o edital, pensei prontamente na possibilidade de articular a discussão de raça e gênero, propondo um projeto denominado "Combatendo desigualdades, desconstruindo preconceitos: negras LGBTs no espaço escolar". Tal ideia partiu de algumas observações já realizadas sobre o espaço escolar e de curiosidades pertinentes sobre as estatísticas referentes à população de travestis e transexuais negras, concluintes do ensino médio. Quais seriam elas? Ou, qual a parcela dessa população que chega a concluir o ensino médio e a ingressar nas universidades?

Esses questionamentos são advindos de outras experiências, como a do ano de 2016, que ao participar da criação e dando aulas voluntariamente em um cursinho de preparação para o ENEM para travestis e transexuais, foi possível perceber que um alto índice delas não havia sequer concluído o ensino fundamental. Em conversas informais, foi alegado que evadiram do espaço

\footnotetext{
2 O EDITAL SEE № 01/2017 - PROJETO: INICIAÇÃO CIENTÍFICA NO ENSINO MÉDIO, EIXO: núcleos de pesquisa e estudos africanos, afro-brasileiros e da diáspora - UBUNTU/NUPEAAS, tinha como objetivo a seleção de projetos de iniciação científica para o desenvolvimento do eixo núcleo de pesquisa e estudos africanos, afro-brasileiros e da diáspora -

UBUNTU/NUPEAAS, no ensino médio da rede estadual de ensino de Minas Gerais, para o processo de seleção de projetos de autoria de estudantes e professores de escolas de Ensino Médio da Rede Estadual de Ensino de Minas Gerais, decorrente da Campanha Afroconsciência da SEE e que integra o Projeto Iniciação Científica no Ensino Médio.
} 
escolar por não suportarem a alta carga de preconceitos que tinham que enfrentar cotidianamente.

Com isso, ao voltar o olhar para a escola em que eu trabalhava, de periferia, com maioria de estudantes negros e algumas alunas travestis, busquei refletir quais as condições de ensino eram oferecidas àquela população na escola e quais as influências em sua permanência no contexto educacional. Assim, durante o desenvolvimento da pesquisa, buscando colocar em discussão não só os preconceitos de gênero e raça, mas também tantos outros diferentes preconceitos que perpassam a vida dos nossos estudantes, além de grupos sociais inferiorizados socialmente, tive interesse em perceber as consequências dos preconceitos na vida de cada um deles.

Sobre isso, na escola em que atuei como professor, percebi que era comum alguns estudantes tentarem inferiorizar o outro, seja em relação ao gênero, à raça ou a qualquer outro tipo de diferença. Os LGBTs eram marcados por meio de xingamentos ligados à sexualidade como: bixinha, boiola, viadinho, etc. Tais apelidos pejorativos demarcam claramente práticas preconceituosas no espaço escolar. Sobre as mulheres, eram corriqueiras as falas de meninos objetificando o corpo da mulher, determinando seu caráter e moral pela quantidade de pessoas que se relacionava ou a roupa que estava vestindo. Em relação aos negros, era comum alunas pedirem para ir ao banheiro e voltarem com os cabelos molhados ou inferiorizar o outro pela sua cor, ou quando íamos assistir a um filme e se apagavam as luzes e outros alunos pediam para estudantes negros sorrirem, tais comentários estavam sempre disfarçados de piadas, e consagravam históricos de desigualdades e discriminações.

Esse projeto foi importante para enfrentar naquele momento intensas discussões sobre a "ideologia de gênero", uma vez que, na cidade de Uberlândia, vereadores tentavam barrar qualquer discussão sobre gênero e sexualidades nas escolas da cidade. Esse projeto tinha como resistência a luta para manterem vivas pessoas consideradas abjetas por uma parcela da população porque

Todas as estratégias de poder vinculadas ao slogan "ideologia de gênero", que buscam intimidar, coibir e impedir qualquer trabalho na escola com os temas gênero e sexualidade, estão contribuindo exatamente para aumentar o número de vidas não vivíveis; aumentar o número de mortes sociais. (PARAísO, 2018, P. 24).

Acreditamos que tais práticas revelam uma sociedade marcada pela desigualdade, pois o preconceito contribui na constituição de desiguais e na consagração de diferenças sociais. Assim, começamos a questionar: Qual o papel da escola na construção de cidadãos e cidadãs que respeitem as 
diversidades? Qual o peso da omissão da escola na sua responsabilidade de criar uma sociedade mais justa e igualitária? Qual o papel da escola, incluindo diretores, supervisores, professores e alunos na construção de ações de combate ao racismo, machismo, homofobia e qualquer tipo de preconceito? Qual a responsabilidade da escola nos altos índices de evasão escolar causados especificamente por práticas preconceituosas?

Entendo que o espaço da escola não é um campo neutro, e é importante pensar a escola e os cotidianos escolares a partir das relações de poder levantadas por Foucault, pois nos permite refletir sobre sujeição e/ou formas e dispositivos que incidem também sobre as ações dos estudantes. Sob a ótica das teorias foucaultianas, podemos perceber justamente os assujeitamentos/resistências, disputas e articulações que produzem representações sociais que incidem sobre formas de agir e pensar dentro e fora do espaço escolar. A partir desse conceito de Foucault, é importante pensar a escola enquanto um dispositivo dentre os inúmeros existentes, que atua na produção, numa relação de poder, da (in) visibilidade de corpos de travestis, negros, mulheres, gordos, ou qualquer um que não se encaixa no padrão normativo de sexo/gênero/raça/classe/religião/capacitismo/etc. Tais relações de poder, presentes nessas disputas na constituição de discursos, e geradoras de desigualdades sociais, integraram e integram meu interesse em perceber/desconstruir/problematizar as diferentes técnicas polimorfas de poder presentes na escola, produzidas dentro e fora dela, geradoras de invisibilidades, mortes sociais, hierarquias e inferiorizações.

Assim, essas pesquisas e ações trataram, sobretudo, de uma forma de analisar os discursos/práticas no espaço escolar, para além do caráter repressivo de poder, procurando pensá-los com "tecnologias positivas de poder", ou seja, objetos/objetivações e sujeitos/subjetividades que se designam nos discursos sob novos procedimentos de poder que

[...] funcionam, não pelo direito, mas pela técnica, não pela lei, mas pela normalização, não pelo castigo, mas pelo controle, e que se exercem em níveis e formas que extravasam do Estado e de seus aparelhos. (FOUCAULT, 1988, p. 17-18).

Pensar as relações históricas entre o poder e os discursos normativos, é uma forma de observar o funcionamento dessa tecnologia complexa permeada por diferentes relações de poder. O poder não é visto aqui como algo superior, que nos atinge impiedosamente como um cometa caindo sobre a terra, mas como redes de poder, presente insidiosamente sobre nosso cotidiano e que não 
[...]se exerce de modo fragmentar e descontínuo; mas que é ou precisa ser vista pelos indivíduos que a ela estão expostos como contínua, perpétua, permanente; que não tenha limites, penetre nos lugares mais recônditos (FOUCAULT, 1998, P. XVIII).

Sobre isso, cabe pensar quais as relações de poder mais imediatas que operam nos espaços escolares? Não por acaso é necessário entender que

[...] o poder não é uma instituição e nem uma estrutura, não é uma certa potência que alguns sejam dotados: é o nome dado a uma situação estratégica e complexa numa sociedade determinada. (FOUCAULT, 1988, p. 103).

Isto é, o poder está difuso nas múltiplas relações sociais. Assim, penso que essas e outras indagações foram/são importantes para tentar perceber o quão presente o racismo, a homofobia, a transfobia, ou outras formas de preconceitos se fazem presentes no espaço escolar, de que maneiras as relações de poder se estabelecem e de que forma esses preconceitos incidem sobre esses/as estudantes acarretando uma possível evasão escolar dessa população. Dessa forma, compreendo que a escola muitas vezes se constitui em um espaço extremamente marcado por desigualdades sociais, onde padrões são constantemente estabelecidos por "relações de poder ainda mais sutis, móveis e dispersas" (FOUCAULT, 1998, P. XVIII), e o outro, o diferente é tentado por essas relações de poder a enquadrar-se na norma, sendo seu corpo compulsoriamente esquadrinhado, identificado e demarcado nessas relações.

Assim, percebo que nas salas de aula o respeito às diversidades e às pluralidades são extremamente raros, contribuindo como instrumento para processos de consolidação de preconceitos e, consequentemente, legitimador das variadas violências contra os sujeitos que se expressam para além da heteronormatividade, das identidades de gênero estabelecidas como hegemônicas, ou outros padrões normativos impostos/estabelecidos. Assim, podemos perceber que

Em vários momentos históricos e em diferentes sociedades, a lógica binária construiu culturalmente um componente negativo e outro positivo, impedindo a pluralidade de identidades, de pensamentos, de crenças. Assim, várias categorias foram sendo criadas e identificadas como o outro diferente. No sentido religioso, político, na saúde (doente), na etnia (o de cor) ou mesmo o outro que optou ou nasceu biologicamente com um sexo considerado inferior; todos eles foram registrados $\mathrm{e}$ normatizados como loucos, deficientes, negros, índios, mulheres, homossexuais, indigentes, estrangeiros, entre tantos 
outros. [...] torna-se "O" inimigo que deve ser combatido, eliminado. (PUGA, 2005, p. 12).

No espaço escolar, não diferente disso, é possível observar que esse outro é corriqueiramente inferiorizado, subjugado, colocado à margem nesses espaços. O normal, o aceito é estabelecido enquanto referência. São os ditos normais, que designam as normas identitárias que definiam os sujeitos e contornavam os limites e caminhos a serem seguidos, caminhos estes que funcionam como balizas ou referências, e que ao desviar-se dessas rotas já estabelecidas, esses sujeitos eram punidos julgados e inferiorizados socialmente. Por isso, pensando nessas relações de poder, essas pesquisas e ações tiveram como objetivo trabalhar com esses seres postos enquanto anormais, inferiorizados, subordinados e designados à morte social. Assim, como Didi-Huberman propõe em seu texto, busco ter "a capacidade de reconhecer no mínimo vaga-lume uma resistência, uma luz para todo o pensamento" e luto para não afundar na "incapacidade em buscar novos vagalumes, uma vez que se perderam de vista os primeiros". (DIDI-HUBERMAN, 2011, p. 67).

Os cotidianos escolares foram/são meu espaço de reflexão, resistência, percepção, problematização e análise das diferentes relações de poder produtoras de desigualdades que instauram padrões e buscam criar caixas/normas para aqueles que compõem/praticam aquele espaço. Assim, busquei refletir sobre essas práticas permeadas pelos preconceitos tentando entender as diferentes formas de repressão que ocorreram/ocorrem nesse espaço, problematizando os discursos que estariam operando ali gerando desiguais/desigualdades, desconstruindo práticas preconceituosas, percebendo aquilo que escapa, propondo enquanto resistência, objetivando práticas que desestruturavam/desestruturam ciclos de opressões permitindo construir e ou reproduzir ações que tivessem como princípios a igualdade e o respeito as diversidades, refletindo sobre o racismo, a homofobia a transfobia, o machismo, ou qualquer forma de preconceito presente na escola.

\section{Metodologia}

A pesquisa utilizou como metodologia estudos bibliográficos, documentais e de campo. Juntos, eles nortearam o desenvolvimento dessas pesquisas e ações. Através de pressupostos teóricos nos campos dos estudos de gênero, sexualidades, dos cotidianos, dos currículos e da educação foi possível realizar análises dos espaços escolares, de práticas e propor ações de resistências. 
Os estudos de caso foram importantes para a elucidação dos problemas encontrados na escola referente aos preconceitos, bem como na preparação de ações que contribuíssem para a minimização do preconceito, da inferiorização e da evasão escolar. Na fase inicial, houve ciclos de estudos de texto, palestras e debates que visaram a formação do grupo de pesquisa, com objetivo de uma melhor aplicabilidade do projeto. Além disso, foi realizada uma análise das formas de preconceitos presentes na nossa escola. A partir daí, iniciamos com as ações. Sobre isso, ainda foi concernente desenvolver entrevistas, que não estão nesse texto, com negros e negras travestis, gays, lésbicas ou bissexuais, analisando preconceitos, estigmatizações ou problemas enfrentados por eles/as no espaço escolar.

Após essas análises, foi verificado se os espaços escolares permitiam a formação de cidadãos e cidadãs que respeitassem as diversidades presentes em nossa sociedade. Cabe ressaltar que os resultados foram utilizados para a promoção de ações que permitiriam que fosse superada a exclusão, a diferenciação e o preconceito em relação ao outro, possibilitando que os estudantes refletissem sobre o machismo, a LGBTfobia, o racismo, ou qualquer outra forma de preconceito e para $\mathrm{q}$ eu aprendessem a respeitar as pluralidades.

No campo das entrevistas, foram utilizados os Termo de Consentimento Livre e Esclarecido aos responsáveis pelos estudantes entrevistados. A entrevista ocorreu na biblioteca em horário de aula e foi gravada a partir do gravador de voz de um celular.

\section{Desenvolvimento da pesquisa/ações}

\section{- Aplicação dos Indicadores de Qualidade da Educação³}

Inicialmente, decidimos diagnosticar o problema dos preconceitos presentes na nossa escola, principalmente o racismo. Organizamo-nos, formando o grupo guardião $0^{4}$ e marcamos o momento para debater e analisar nossas práticas e escola. Fizemos os cartões verde, amarelo e vermelho, e

\footnotetext{
${ }^{3}$ Considerando a magnitude e complexidade da questão racial no Brasil e, especificamente, na educação brasileira, os Indicadores da Qualidade na Educação Relações Raciais na Escola foram elaborados visando contribuir com a superação do racismo nas escolas. Auxilia na construção de um retrato da implementação da Lei n. 10.639/2003, a qual introduziu a obrigatoriedade do ensino da história e da cultura africanas e afro-brasileiras, bem como da educação das relações etnicorraciais na educação básica (pública e privada).

${ }^{4} \mathrm{O}$ grupo guardião consiste em formar uma equipe composta por professores, estudantes, direção, supervisão, secretaria e comunidade escolar, responsáveis por guiar a avaliação dos Indicadores de Qualidade na Educação.
}

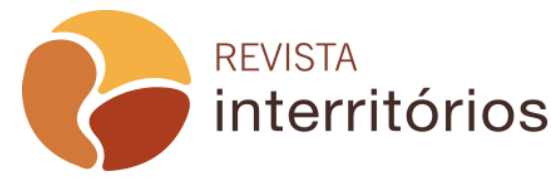

Interritórios | Revista de Educação Universidade Federal de Pernambuco, Caruaru, BRASIL | V.6 N.10 [2020] 
promovemos debates sobre cada ponto lido no livro do INDIQUE. Assim, durante cada debate, o relator anotava as mudanças necessárias e observações feitas por cada participante. Observar e debater sobre nossa escola foi extremamente importante, o primeiro passo para tentar nos libertar das amarras dos preconceitos.

Figura 1: Livro para aplicação dos Indicadores de Qualidade na Educação.

Relações Raciais na Escola.

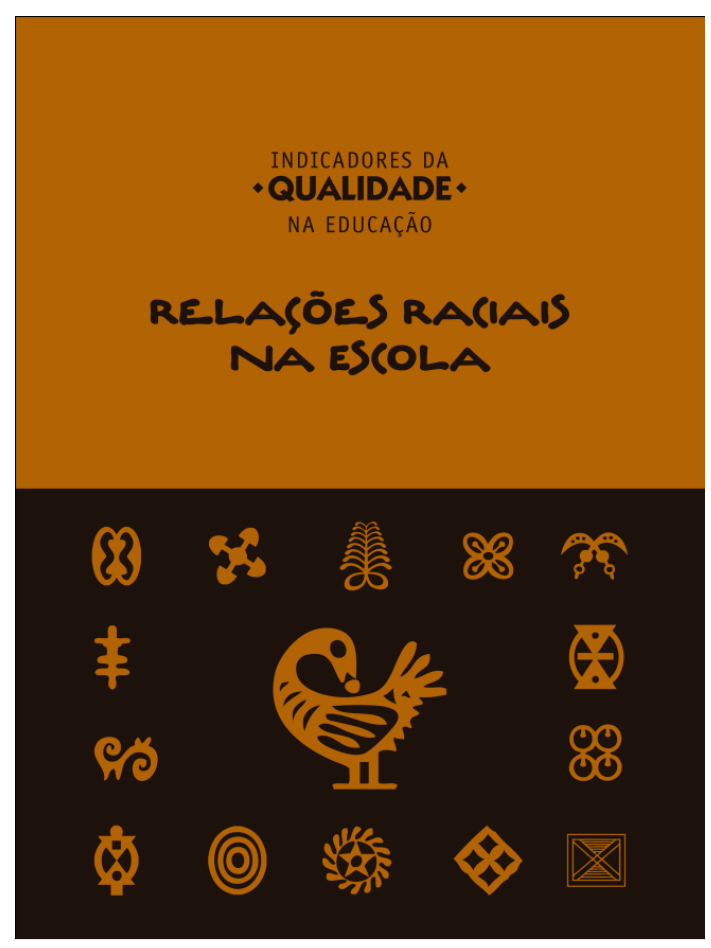

- Construção do painel da diversidade (GRAFITE) 
Figura 2, 3, 4: Painéis de grafitagem realizados na escola
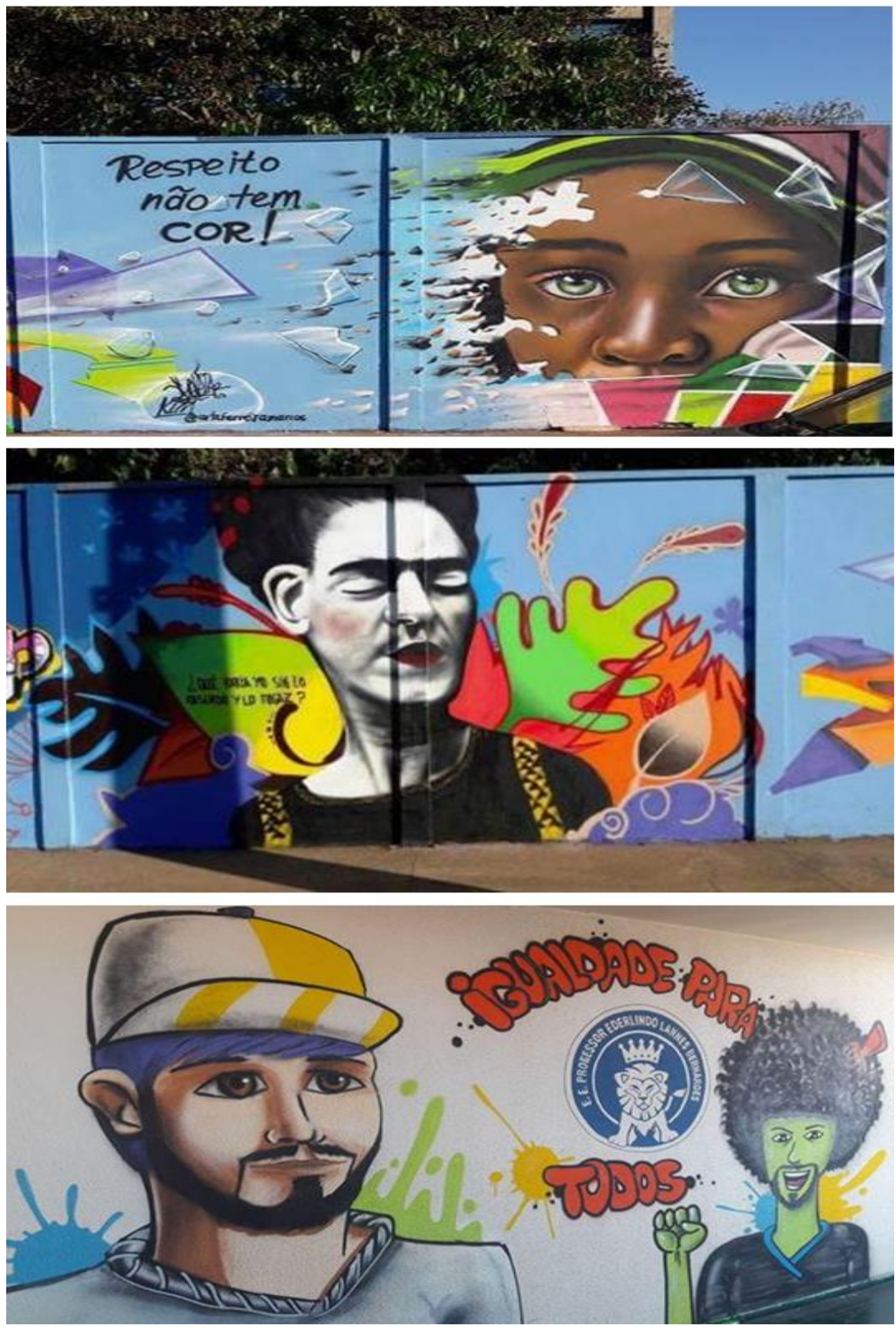
Nesse momento convidamos estudantes que gostassem da arte do grafite para desenhar nas paredes e muros da escola. Nessas ações, prontamente percebemos que iríamos precisar do apoio de profissionais da área. Assim, decidimos convidar grafiteiros da cidade, conhecidos e admirados pelos estudantes, para que fizessem em conjunto a grafitagem dos painéis na fachada e interior da escola. Neles, foram tratados acerca dos temas machismo, racismo e homofobia. É importante ressaltar que nesse momento fizemos acordo com grafiteiros reconhecidos na cidade e nacionalmente, propondo que fossem realizadas grafitagens que tratassem da diversidade, enaltecendo a luta das mulheres, dos LGBTs e dos negros. Essa grafitagem ocorreu em um sábado, com a presença dos/as alunos/as, inclusive aprendendo técnicas dessa arte. Abaixo algumas imagens desse momento:

- Debates com Diretora de Igualdade Racial da Prefeitura de Uberlândia DIIGUAL / Coordenadora de Diversidade Sexual da Prefeitura de Uberlândia / Membro do Núcleo de Estudos Afro-Brasileiros NEAB-UFU / Professora de História da UFU membro do Núcleo de Estudos de Gênero NEGUEM - UFU5

Nessa fase, levamos para a escola representantes de movimentos sociais, de organizações que promovem o debate sobre a opressão de determinados grupos na sociedade, permitindo problematizar preconceitos presentes no espaço escolar. Essas rodas de conversas com os debatedores do movimento negro (NEAB/ DIIGUAL), de mulheres e LGBT permitiram discutir com professores/as, alunos e alunas, corpo diretivo e supervisão sobre a importância do respeito às diferenças e da construção de ações que permitissem a formação de uma escola mais justa e igualitária.

- Debate com membros da Associação Nacional de Travestis e Transexuais - ANTRA / do Fórum Nacional de Travestis e Transexuais, Negras e Negros - FONATRANS /e membros do Conselho Nacional Contra Discriminação LGBT - CNCD/LGBT ${ }^{6}$

\footnotetext{
${ }^{5}$ Nesse momento convidamos para o debate Sayonara Naider Bonfim Nogueira, professora de geografia, diretora do Núcleo de Diversidade Sexual da Prefeitura de Uberlândia, membro do Instituto Brasileiro Trans de Educação. Pollyanna Fabrini Silva, professora de sociologia, Diretora de Igualdade Racial da Prefeitura de Uberlândia, pesquisadora do Núcleo de Estudos Afro-Brasileiros. Régis Rodrigues Elisio, coordenador de assuntos estudantis do Núcleo de Estudos Afro-Brasileiros, professor de História. Jorgetânia da Silva Ferreira, professora de História, membro do Núcleo de Estudos de Gênero da UFU.

${ }^{6}$ Convidamos para debater na nossa escola Keila Simpson, residente em Salvador, Bahia, é presidente da Associação Nacional de Travestis e Transexuais - ANTRA, membro do Conselho Nacional Contra Discriminação LGBT - CNCD/LGBT. Pâmela Volp, residente em Uberlândia, Minas Gerais, é vereadora em Uberlândia, membro da ANTRA, Jovanna Cardoso Silva, residente em Picos, Piauí, é membro do CNCD/LGBT, presidente do Fórum Nacional de Travestis e Transexuais, Negras e Negros. Anyky Lima, residente em ativista travesti, membro da ANTRA. Fernanda Benvenutty, ativista travesti, membro da ANTRA.
}

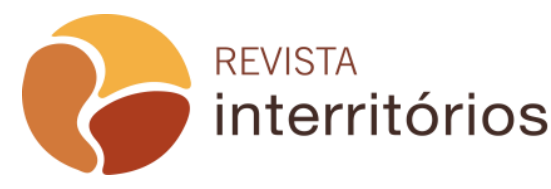

Interritórios | Revista de Educação Universidade Federal de Pernambuco, Caruaru, BRASIL | V.6 N.10 [2020] 
Nesse momento, também foram feitos vários debates com representantes do movimento negro, de travestis e associações de travestis e transexuais negras. O objetivo era repensar o espaço escolar, nossas práticas, fazendo com que todo corpo que a compõe identificasse práticas discriminatórias e refletisse sobre suas ações. Esse momento foi importante para repensar sobre a presença do racismo e outras formas de preconceitos na escola e na sociedade. Nessas palestras, contamos com palestrantes de diferentes estados do Brasil, como Piauí, Paraíba, Minas Gerais, Bahia. Para além dessas questões, o objetivo foi problematizar a imagem das travestis, mostrando os diferentes espaços que elas ocupam, além da sua história de luta por direitos em nossa sociedade.

\section{Gravação de vídeo relato/denúncia sobre práticas discriminatórias ocorridas na escola}

Nesta etapa, gravamos um vídeo com estudantes que desejaram relatar e expor práticas discriminatórias, referentes ao racismo e homofobia, ocorridas no espaço escolar. Em um dos casos, foi relatada a homofobia sofrida por um estudante que ouviu de uma supervisora escolar que iria para o inferno por ser gay e usar brincos, caso ele não mudasse seu jeito de ser, não seria feliz. Esse relato gerou uma reflexão sobre o papel da escola no combate a esse tipo de violência, nos levando a pensar: O que fazer quando isso ocorre? Qual o papel da escola no acolhimento a esse aluno discriminado? Qual apoio a escola deveria ter dado? Esse acontecimento revela a construção do ser homem e ser mulher estabelecidos socialmente, determinando que o uso de brincos, isto é, assumir aspectos da identidade feminina significa, obrigatoriamente, o não acesso à felicidade. Essas e outras reflexões apontadas foram determinantes para estabelecer protocolos para situações como essa, ou seja, a escola deveria, a partir daquele momento, saber como lidar com essas situações de constrangimentos, preconceitos e humilhações.

\section{Entrevistas individuais com negras/LGBTs estudantes da escola}

O objetivo foi que estudantes LGBTs negras denunciassem por meio das entrevistas sigilosas de que forma a discriminação afetou ou não suas vidas e seu desempenho escolar. Por meio dessa pesquisa, pudemos perceber que as práticas de racismo e homofobia ocorrem corriqueiramente e afetam profundamente a vida dos nossos estudantes. Os professores e a escola muitas vezes não dão o devido apoio às vítimas desses preconceitos. Até porque não há apoio psicológico disponibilizado pelo estado. Durante essas entrevistas, foi possível percebermos que o racismo e a homofobia são práticas presentes na escola e que os danos causados na vida de estudantes são extremamente sérios 
e pouco tratados. Subestimamos tais acontecimentos, e a escola, em geral, não leva a sério as denúncias. Recebemos em nossa escola estudantes trans que deixaram de estudar em outras escolas por sofrerem preconceitos, por não terem seu nome social respeitado. Assim como tivemos relatos de estudantes da nossa própria escola que deixou por dois anos de estudar por gordofobia. Esses e outros casos revelam que as discriminações e os preconceitos devem ser vistos com atenção e reflexão, principalmente quando provoca desinteresse do estudante pela escola.

\section{- Evento "Escola SEM Preconceitos"}

Após termos promovido várias discussões, palestras, análises da nossa escola, decidimos que todo o turno matutino, inclusive todos os professores se envolveriam em uma grande pesquisa/ação sobre preconceitos existentes no espaço escolar. Livremente, cada professor pôde escolher qual tema iria desenvolver. Foi disponibilizado um espaço no quadro, onde cada professor apontaria qual tema iria trabalhar, com a devida turma por ele coordenada. Durante três meses, cada professor coordenador de turma, após eleger seu tema, deveria desenvolver suas pesquisas. Esse projeto foi concluído com um dia, marcado para um sábado, aberto à comunidade, com a exposição dos trabalhos realizados. Tal proposição teve como objetivo fazer com que toda a escola repensasse o saber/fazer, discutindo sobre preconceitos e percebendo 0 quão enraizado ele está. Para além dessas questões, o objetivo também era criar rizomas, isto é, caso o professor coordenador não estivesse mais presente na escola, que os projetos de combate a discriminações caminhassem pelas mãos de outros professores que ali estivessem, por isso, pensamos em trabalhar em redes, na interação, na ação conjunta, na construção coletiva do projeto. Sobre os temas trabalhados, foram eleitos os seguintes: gordofobia, racismo, LGBTfobia, capacitismo, machismo, intolerância religiosa, padrões estéticos/beleza. Nesses trabalhos, foram feitas discussões de esclarecimento, e algumas perguntas nortearam os debates. Nesse momento, de construção do evento, os debates ocorreram individualmente com cada professor coordenador de turma, e as dúvidas, andamentos, dificuldades, eram expostas na sala de professores em reuniões e também em intervalos de aula e recreio. Sobre as perguntas que nortearam os debates de sala, podemos destacar:

- Você aceitaria caso tivesse um filho homossexual?

- Você já sofreu alguma forma de preconceito na escola?

- Você já teve alguma prática preconceituosa com algum colega?

- Você concorda com cotas raciais para universidades e concursos públicos?

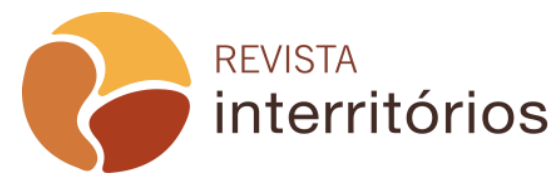

Interritórios | Revista de Educação Universidade Federal de Pernambuco, Caruaru, BRASIL | V.6 N.10 [2020] 
- Você sabia que existem cotas raciais para universidades e concursos públicos?

Essas perguntas nortearam debates e pesquisas e possibilitaram expor como diferentes formas de preconceitos ou como determinadas concepções ainda estão presentes em nosso imaginário e, consequentemente, refletindo em nossas práticas sociais.

\section{Resultados e Discussão}

O estudante entrevistado colocou em xeque nossa atuação enquanto escola e nos propôs repensar nossas práticas ao lidar com atitudes de preconceitos no ambiente escolar ao relatar que

Quando eu sofri preconceito eu procurei a escola e aí teve gente que falou para mim que não era homofobia que não era racismo aí ficou sem fazer alguma coisa aí eu conversei com a minha mãe e ela falava assim que ia ficar tudo bem... não sei o quê e aí eu não tinha nenhum apoio aí eu ficava meio perdido Eu também não sabia me defender direito em relação aos preconceitos que eu sofria.. teve racismo por causa do meu cabelo quando eu estava na fase de transição minha autoestima estava baixa e o pessoal começou a falar de mim que eu era pretinho [...] eu não tinha nenhum apoio mesmo na escola e nem minha mãe me apoiava mas depois minha mãe viu que era uma coisa que eu queria começou me apoiar e me ajudar (Estudante entrevistado, 2017).

Tal declaração fez com que esse projeto se tornasse realidade e que lutássemos por uma escola plural, diversa, em que diferenças não fossem/sejam motivo de exclusão ou inferiorização social. Para além dessa declaração exposta pelo estudante, outra foi essencial no caminho a ser pensado

eu acho que o pessoal da escola Tem que ler mais as coisas porque eles falaram que não era racismo que não era homofobia E era homofobia era racismo $E$ aí você fica perdido sem saber o que vai fazer depois disso daí você fica meio perdido e eu acho que eles tinham que ter um apoio psicológico na escola para oferecer pra gente... Falar sobre qualquer coisa porque tem gente que sofre muita coisa tem professor que sabe e não fala sobre o assunto sobre depressão, homofobia tem gente que sofre preconceito na sala... são poucos que falam sobre esses assuntos em sala de aula (Estudante entrevistado, 2017). 
Esse relato nos mostrou quais percepções de um estudante que se identifica enquanto negro e gay dentro de um ambiente recheado de preconceitos. Como solução ele propõe diálogo, conversa, apoio, reflexões, discussões, afirma ainda, que tem muita gente sofrendo preconceitos dentro da escola e pouco se é falado sobre o tema.

Assim, partimos desse relato que me motivou a propor mudanças no cotidiano daquela escola. Durante esse trabalho, que se tornou um projeto de escola, conjuntamente aprendemos a olhar minuciosamente e fomos capazes de perceber essa cultura da estigmatização, da inferiorização do outro. A partir dessas observações e reflexões fomos capazes de criar ações capazes de subverter esses ciclos de violências que percebemos estarem naturalizados nos discursos, nas falas, nas agressões físicas e/ou verbais, ocorridas dentro das escolas. Fomos capazes de perceber a construção histórica e política dos discursos e das identidades no interior de um sistema cultural androcêntrico, eurocêntrico, patriarcal, racista e transfóbico que exclui e designa ao outro o caráter de inferioridade, instituindo desigualdades, assimetrias e hierarquizações sociais.

Acreditamos que ao se conhecer a realidade do ciclo de opressão vivenciada por estudantes outros, aqueles que não se encaixam nas normas/padrões de sexo, gênero, raça, classe, religião, beleza, foi possível trilhar novos caminhos de respeito e tolerância, desconstruindo ciclos de inferiorização social.

Assim, como Foucault, penso que

\begin{abstract}
Pensar, pelo contrário, é passar; é questionar essa ordem, surpreender-se pelo fato de sua presença aí, indagar-se sobre o que tornou possível essa situação, procurar- ao percorrer suas paisagens- os vestígios dos movimentos que a formaram, além de descobrir nessas histórias, supostamente jacentes, o modo como e até onde seria possível pensar diferente.( CERTEAU, 2011, p. 117-118).
\end{abstract}

Assim, ao longo do desenvolvimento desse trabalho, percebemos que os preconceitos, a violência, as estigmatizações são corriqueiras na escola, e que causam danos talvez irreparáveis na vida dos(as) estudantes. Portanto, realizamos ações que visassem quebrar o ciclo de preconceitos dentro da nossa escola, em que o primeiro passo foi rever nossas próprias práticas e assim ir trilhando caminhos de respeito e valorização das diversidades, construindo na escola um espaço plural em que todos fossem/sejam respeitados como são. Desta forma, o trabalho 
Tratava-se de desnaturalizar as operações que levam os discursos produzidos em tais lugares a falarem em nome do real e da verdade sobre o Outro, silenciando-o e fabricando os modos como ele deve ser percebido, subjetivado, objetivado, assistido, dominado, controlado e governado (FERRAÇO, SOARES, ALVES, 2018, p. 73).

Não por acaso, penso que essas ações desenvolvidas no espaço escolar enquanto contra hegemônicas e que esses "procedimentos populares (também "minúsculos" e cotidianos) jogam com os mecanismos da disciplina e não se conformam com ela a não ser para alterá-los" (CERTEAU, 1998, p. 41). Assim, essas ações se tornaram essenciais por propor a reflexão sobre a evasão escolar, as trajetórias escolares, resistências, escapes e fugas. A pesquisa e as ações foram pensadas enquanto tática, isto é,

Maneiras de fazer: vitórias do "fraco" sobre o mais "forte", (os poderosos, a doença, a violência das coisas ou de uma ordem etc.) pequenos sucessos, arte de dar golpes, astúcias de "caçadores, mobilidades da mão-de-obra, simulações polimorfas, achados que provocam euforia, tanto poéticos quanto bélicos". principalmente das/os estudantes LGBTs para sobreviverem naquele espaço. (CERTEAU, 1998, p. 47)

Assim, percebemos que esse projeto se tornou, ao longo de sua execução, importante por contribuir para mover estruturas dadas, estáveis, cristalizadas, denunciando/problematizando práticas que determinavam dizer em nome da verdade estabelecendo o central, o padrão e inferiorizando estudantes que se desviavam da norma.

\section{Conclusões}

Pensamos:

[ ... ] os cotidianos escolares como espaçostempos de criação e de articulação de conhecimentos, de emancipação e de invenção da vida e não apenas como um domínio social no qual só existe passividade, submissão, repetição, reprodução e consumo do que é criado em outros contextos (como as políticas educativas oficiais, as disciplinas científicas e o mercado). (FERRAÇO, SOARES, ALVES, 2018, P. 91).

Os cotidianos escolares praticados ultrapassam o domínio do currículo prescritivo, isto é, das imposições deterministas. Os cotidianos, os currículos, são marcados pelos desvios das práticas, a 
escola é plural, diversa, dinâmica, onde o controle total dessas instituições é impossível, os desvios estão sendo constantemente produzidos, não há domínio total, fugas, fossos, fissuras e bricolagens estão sendo produzidas. O padrão se estabelece, relações de poder são produzidas corriqueiramente na construção desses cotidianos, gerando desiguais engendrados nessas relações de poder, inferiorizados em diferentes práticas como as do preconceito, do xingamento, do isolamento etc. Entretanto, este projeto se coloca na contramão dessas normatividades, propondo/sendo tática, fuga, escape, resistência. Principalmente em tempos de "escola sem partido", combate a "ideologia de gênero" e a proliferação de discursos machistas, racistas, homofóbicos. Após o desenvolvimento desse projeto, notamos inumeráveis transformações no cotidiano escolar a partir dessas discussões, dentre elas, uma maior força de estudantes e professores para o enfrentamento de práticas discriminatórias.

Por fim, acreditamos que esse projeto foi um importante espaço para problematização, reflexão e construção de saberes outros, que permitiram pensar numa sociedade mais justa, igualitária e democrática onde cada um seja respeitado em sua plural diferença.

\section{REFERÊNCIAS}

BUTLER, Judith. Problemas de gênero: Feminismo e subversão da identidade.

Rio de Janeiro: Civilização Brasileira, 2012.

BUTLER, Judith. Corpos que pesam: sobre os limites discursivos do 'sexo'. In: LOURO, Guacira. L. O Corpo Educado: Pedagogias da Sexualidade. Belo Horizonte, Autêntica, 2013.

CERTEAU, Michel de. A invenção do cotidiano - 1. Artes de fazer. Petrópolis: Vozes, 1994.

CERTEAU, Michel de. A cultura no plural. Campinas, SP: Papiros, 1995.

CERTEAU, Michel de. História e Psicanálise - Entre ciência e ficção. Belo Horizonte, Autêntica, 2011.

DIDI-HUBERMAN, Georges. Sobrevivência dos vaga-lumes. Belo Horizonte: Ed. UFMG, 2011.

FERRAÇO, Carlos Eduardo. SOARES, Maria da Conceição Silva. ALVEZ, Nilda. Michel de Certeau e as pesquisas nos/dos/com os cotidianos em educação. Rio de Janeiro: EdUERJ, 2018.

FOUCAULT, Michel. História da Sexualidade I: a vontade de saber. Rio de Janeiro: Graal, 2011 
FOUCAULT, Michel. Microfísica do Poder. Rio de Janeiro: Graal, 1986.

FOUCAULT, Michel. Em Defesa da Sociedade. Curso no Collége de France (19751976) São Paulo: Martins Fontes, 1999.

LAURETIS, Teresa de. A tecnologia do gênero. In: HOLANDA, Heloisa Buarque. Tendências e impasses. Rio de Janeiro: Rocco, 1994

LOURO, Guacira Lopes. O Corpo Educado. Pedagogias da Sexualidade. Belo Horizonte, Autêntica, 2013.

PARAÍSO, Marlucy Alves. Fazer do caos uma estrela dançarina no currículo: invenção política com gênero e sexualidade em tempos do slogan "ideologia de gênero". In: PARAísO, Marlucy Alves e SILVA, Maria Carolina de. Pesquisas sobre currículos, gêneros e sexualidades. Belo Horizonte: Mazza Edições. 2018.

PUGA, Vera Lucia. Útero e Loucura: medicina e moralidade. Anos 1942-1959. In: CARDOSO, Heloisa Helena Pacheco e MACHADO, Maria Clara Tomaz (orgs.). História: narrativas plurais, múltiplas linguagens. Uberlândia, EDUFU, 2005. 